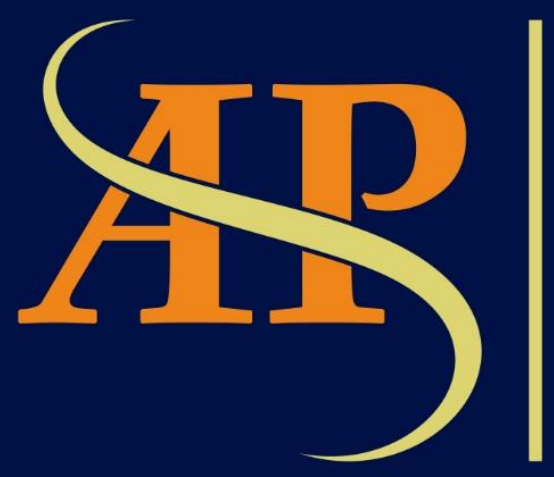

JURNAL ASIA PACIFIC STUDIES

Journal of International Relations Study Program Faculty of Social and Political Sciences

Universitas Kristen Indonesia

Volume 2 | Number 1 | January - June 2018 


\title{
EKSISTENSI JEPANG DAN TIONGKOK DALAM GEOPOLITIK ENERGI DI ASIA TENGAH
}

\author{
${ }^{1}$ Ayu Suhartini, ${ }^{2}$ Dian Permata Pratiwi, ${ }^{3}$ Jorshy Amanda Sudarno, ${ }^{4}$ Shybill Natalia de Queljoe, \\ dan ${ }^{5}$ Syahrir Roni Geyashra \\ ${ }^{1-5}$ Program Studi Hubungan Internasional, Universitas Kristen Indonesia, Jalan Mayjen Sutoyo No. 2, Cawang, \\ Jakarta Timur, 13630, Indonesia \\ I'ayu.suhartini105@gmail.com, ${ }^{2}$ dianpermatakoba@gmail.com,3jrshyamnda@gmail.com, \\ shybillnatalia15@gmail.com, ${ }^{5}$ ronisyahrir@gmail.com
}

\begin{abstract}
In addition to its existence stretching along Silk Road between Europe and East Asia which later made it the heart of Euroasia, the Central Asia region is also a region rich in energy resources, specifically oil and natural gas. These two factors then brought the region of Central Asia to develop into the second largest oil and gas producing region in the world, after the Middle East. This makes the Central Asian region as an arena as well as a battle theater for energy interests between western countries, Russia, China, Japan, South Asian countries and the Middle East. Japan and China particulary, in the past decade began to show their interest and concentration in this region. This can be seen through the establishment of the 2004 Central Asia Plus Japan Dialogue and the 2006 Official Development Assistance (ODA) by Japan. Do not want to fall behind, in 2013 through its President, Xi Jinping, China building the cooperation with the Central Asia through the One Belt One Road $(O B O R)$ initiative. The purpose of this paper is to explain how the existence of Japan and China and their influence in the dynamics of geopolitical energy in the Central Asian region. To complete this paper, the author used qualitative research methods. From this paper, it was found that the existence of Japan and China had positive impact on the dynamics of energy geopolitics in the Central Asia region.
\end{abstract}

Keywords: Geopolitical energy, oil, natural gas, Japan, China, Central Asia.

\begin{abstract}
Abstrak
Selain keberadaannya yang terbentang di sepanjang Silk Road antara Eropa dan Asia Timur sehingga menjadikannya jantung dari Euroasia, Asia Tengah juga merupakan wilayah yang kaya akan sumber daya energi terutama minyak dan gas alam serta penghasil terbesar kedua di dunia setelah Timur Tengah. Hal ini membuat kawasan Asia Tengah sebagai arena sekaligus teater pertempuran kepentingan energi antara negara-negara barat, Rusia, Tiongkok, Jepang, negara-negara Asia Selatan dan Timur Tengah. Jepang dan Tiongkok secara khusus dalam dekade terakhir mulai menunjukan minat dan konsentrasinya pada kawasan ini. Terbukti melalui pembentukan Central Asia Plus Japan Dialogue tahun 2004 dan Official Development Assistance (ODA) tahun 2006 oleh Jepang. Tidak ingin ketinggalan pada tahun 2013 melalui Presidennya, Xi Jinping, Tiongkok membangun kerjasama melalui inisiatif One Belt One Road (OBOR). Adapun tujun dari tulisan ini adalah untuk menjelaskan bagaimana eksistensi dan pengaruh dari keberadaan Jepang dan Tiongkok dalam dinamika geopolitik energi di kawasan Asia Tengah. Dalam menyelesaikan tulisan ini, penulis menggunakan metode penelitian kualitatif. Dari tulisan ini didapatkan bahwa keberadaan Jepang dan Tiongkok cukup memberikan pengaruh positif bagi dinamika geopolitik energi di kawasan Asia Tengah.
\end{abstract}

Kata Kunci: Geopolitik energi, minyak bumi, gas alam, Jepang, Tiongkok, Asia Tengah 


\section{Pendahuluan}

\subsection{Latar Belakang}

Jean-Marie Chevalier mendefinisikan geopolitik energi sebagai perimbangan kekuasaan di antara negara dan perusahaan-perusahaan dalam rangka mengakses sumber daya energi serta melakukan pengaturan terhadap sumber daya dan isu-isu terkait energi. Bagi negara eksportir, geopolitik energi sering diasosiasikan dengan perampasan uang minyak dan gas serta alokasinya di dalam proses pembuatan keputusan. Sedangkan bagi negara importir, geopolitik energi adalah salah satu kepentingan nasional negara yang vital sehingga dapat mempengaruhi stabilitas negara. Kemudian menurut CSIS (Center for Strategic \& International Studies) "The Geopolitics of Energy identifies and examines the relevant drivers that are likely to dictate future trends in energy consumption and fuel choices in the context of a shifting geopolitical landscape, taking into account the attendant economic, foreign policy, energy security, and environmental consequences and priorities."

Sepanjang sejarah dunia, energi merupakan pendorong pertumbuhan ekonomi, sumber kekuatan militer, dan penentu utama kesejahteraan rakyat. Pada masa Revolusi Industri, negara-negara di dunia masih sangat tergantung dengan batu bara. Pada 1912, tren energi global mulai berubah ketika British Royal Navy beralih dari penggunaan batu bara menjadi minyak. Hal ini banyak mengubah konstelasi politik internasional karena membuat negaranegara yang kaya akan minyak menjadi sekutu yang penting bagi negara-negara kuat. Suplai energi di pasar energi global masih didominasi oleh OPEC. Munculnya Asia Tengah sebagai sumber energi global yang baru berkontribusi terhadap keamanan energi dunia, terutama bagi negara-negara barat. Hal ini tidak bisa dilepaskan dari faktor geografis kawasan Asia Tengah yang sangat strategis karena berbatasan langsung dengan Rusia, Tiongkok dan juga sangat dekat dengan Asia Selatan, Timur Tengah, dan Eropa.

Perkenalan mengenai Asia Tengah maka dapat dibantu dengan dua fitur yakni dari segi historis dan segi geografis. Dimulai dari faktor historis, kawasan Asia Tengah kerap disebut sebagai masa lalu Uni Soviet. Sistem yang diterapkan pun merupakan hasil dari adopsi peninggalan Uni Soviet. Salah satu bentuk contoh dari adopsinya merupakan sistem pengendalian perekonomian Asia Tengah diatur serta dikendalikan oleh negara, sehingga memiliki regulasi yang rumit serta kurang diverifikasi. Negara-negara termiskin yang ada di kawasan ini sangat bergantung pada pengiriman uang yang dilakukan oleh dunia dan menepati peringkat kedua dan kelima. Hal ini pun menjadikan sebagian besar tenaga kerja yang berasal dari negara mereka bekerja di Rusia (Nunlist and Bieri 2016). Dari faktor geografis, Asia Tengah diisi oleh negara Kazakhstan, Uzbekistan, Kyrgyzstan, Turkmenistan, dan Tajikistan. Asia Tengah merupakan wilayah kawasan yang dikelilingi oleh daratan dari padang pasir yang luas serta stepa hingga beberapa gunung yang tertinggi yang ada didunia. Dan bersama-sama mereka mengatur populasi yang tumbuh dengan pesat. Kawasan ini terbentang sepanjang Silk Road antara Eropa dan Asia Timur, sehingga kerap disebut sebagai wilayah jantung dari "Eurasia". Dari segi posisi yang strategis, wilayah Asia Tengah menjadi wilayah yang kaya. Dimana Kazakhstan menjadi wilayah yang kaya akan kandungan minyak, Turkmenistan dan Uzbekistan kaya akan cadangan kandungan gas alam. Serta dua negara kecil seperti Kyrgyzstan dan Tajikistan merupakan wilayah pegunungan dan tidak memiliki banyak sumber daya alam diantara negara yang ada wilayah Asia Tengah lainnya. 


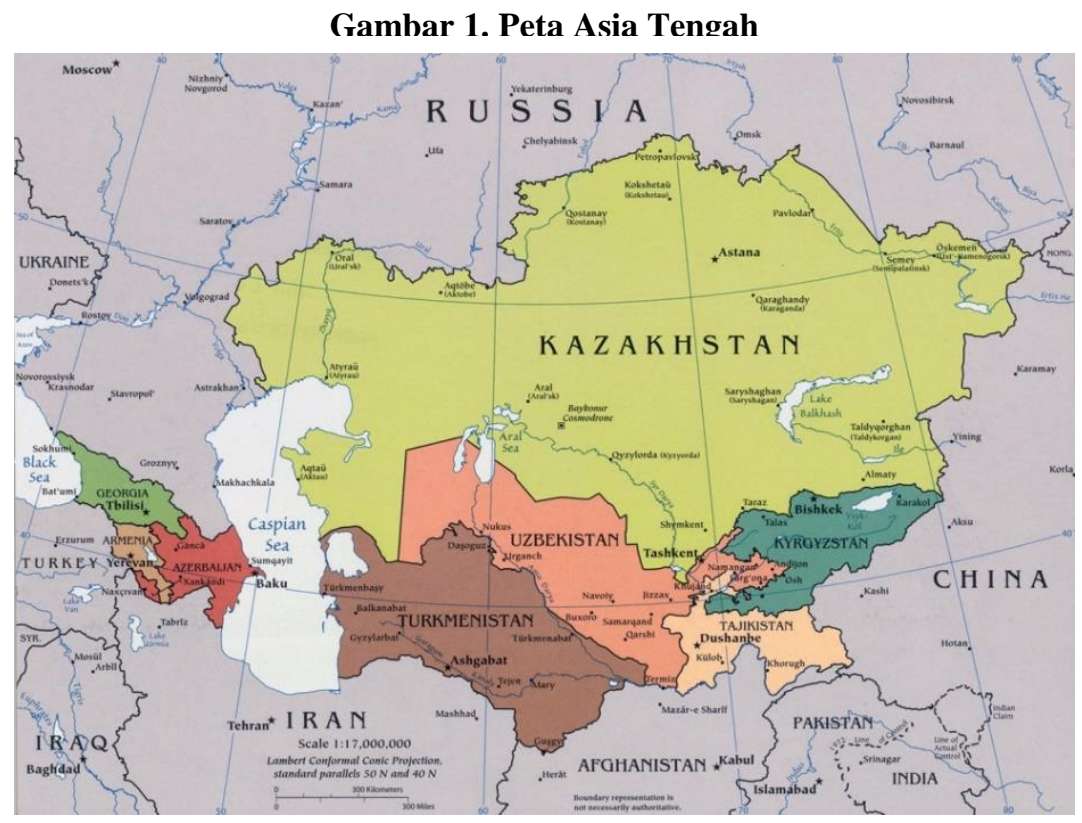

Sumber: nationsonline.org (Political Map of Central Asia)

Dari 1920-an sampai Perang Dingin berakhir, akses terhadap sumber daya energi di Asia Tengah dikuasai oleh Uni Soviet. Tahun 1960 - 1988, pembangunan pipa-pipa untuk menyalurkan gas dari Asia Tengah ke Uni Soviet dilakukan. Pasca-Perang Dingin yang ditandai dengan pecahnya Uni Soviet, negara-negara di Asia Tengah mulai secara perlahan melonggarkan sedikit cengkraman Rusia terhadap sumber daya energi di kawasan tersebut. Hal ini dilihat sebagai keputusan strategis karena dengan melonggarkan hubungannya dengan Rusia, maka negara-negara Asia Tengah bisa membuka diri menjadi alternatif produsen energi global. The Big Three di kawasan Asia Tengah dalam sektor energi adalah: Kazakhstan, Turkmenistan, dan Uzbekistan. Di awal era 1990-an, minyak dan gas menjadi penyangga perekonomian dan sumber pemasukan utama bagi negara-negara Asia Tengah, khususnya: Kazakhstan (55\%), Turkmenistan (86,21\%), dan Uzbekistan (33\%).

Asia Tengah berkembang menjadi kawasan penghasil minyak dan gas terbesar kedua di dunia, setelah Timur Tengah. Hal ini menjadikan kawasan Asia Tengah sebagai arena sekaligus teater pertempuran kepentingan energi antara negara-negara barat, Rusia, Tiongkok, Jepang, negara-negara Asia Selatan dan Timur Tengah. Pada pertengahan 2000-an, Tiongkok adalah negara yang memutus monopoli energi Rusia di kawasan Asia Tengah, khususnya monopoli terhadap minyak Kazakhstan, gas Turkmenistan dan Uzbekistan. Disusul oleh Uni Eropa pada 2004 yang mulai membangun dialog untuk membuka kanal kerja sama dengan Asia Tengah dan pada 2007, serta Jepang yang juga memulai dialog 'Asia Tengah plus Jepang' pada tahun yang sama.

\subsection{Rumusan Masalah}

Bagaimana eksistensi dan pengaruh dari keberadaan Jepang dan Tiongkok dalam dinamika geopolitik energi di kawasan Asia Tengah?

\subsection{Maksud dan Tujuan}

1.3.1 Tujuan Penelitian

Tujuan utama dalam penelitian ini adalah :

1.3.1.1 Mengetahui dan memahami skema penyebaran sumber daya energi di Asia Tengah 
1.3.1.2 Mengetahui peran Jepang dalam Geopolitik Energi di Asia Tengah

1.3.1.3 Mengetahui peran Tiongkok dalam Geopolitik Energi di Asia Tengah

1.3.2 Manfaat Penelitian

Manfaat penulisan penelitian ini adalah:

1.3.2.1 Penelitian ini diharapkan dapat menambah sumbangan pemikiran pemahaman mengenai Geopolitik Energi di Asia Tengah

1.3.2.2 Penelitian sebagai sumbangsih untuk melengkapi penelitian-penelitian yang sudah ada sebelumnya mengenai Eksistensi Jepang dan Tiongkok dalam Geopolitik Energi di Asia Tengah

\subsection{Kegunaan Penelitian}

1. Bagi Penulis, Penelitian ini berguna untuk memperdalam pemahaman Penulis dalam Geopolitik Energi

2. Bagi perguruan tinggi, hasil penelitian diharapkan dapat menjadi dokumen akademik yang berguna untuk dijadikan acuan bagi sivitas akademika.

3. Bagi Pihak Lain, semoga hasil penelitian ini dapat dijadikan bahan referensi yanh bermanfaat.

\section{Kerangka Pemikiran}

\subsection{Teori Sistem Dunia (World System Theory)}

Teori Sistem Dunia (World System Theory) merupakan teori yang dikembangkan oleh Immanuel Wallerstein, seorang sosiologis Amerika pada tahun 1970-an. Wallerstein sangat menantang ilmu sosial modern melalui konsepnya tentang sistem sosial historis. Argumennya adalah bahwa masyarakat tidak boleh disamakan dengan negara tertentu, tetapi pada skala yang lebih besar dari sistem sosial. Menurut Wallerstein, sejak sekitar 1450 sistem sosial telah menjadi ekonomi dunia kapitalis. Dalam teori ini, kekuatan geopolitik primer disebut kekuatan hegemonik. Dasar hegemoni adalah kekuatan ekonomi yang diterjemahkan menjadi pengaruh dominan dalam perdagangan dan keuangan global. Pemeliharaan ekonomi-kapitalis dunia dalam bentuk yang menguntungkan kekuatan hegemonik kadang-kadang membutuhkan kekuatan militer. Hegemoni dilihat sebagai suatu proses ekonomi untuk tujuan-tujuan tertentu, dan bukan kebajikan politik global seperti pada teori World Leadership Modelski. Mirip dengan model Modelski, kekuatan hegemonik muncul dari periode konflik global, tetapi Wallerstein bersikeras bahwa Amerika Serikat saat ini mengalami penurunan relatif dalam dominasi globalnya. Satu perbedaan penting lainnya adalah bahwa dalam model Modelski selalu ada pemimpin dunia, meskipun kekuatannya bersifat siklus. Bagi Wallerstein, periode hegemoni jarang terjadi. Jadi, jika hegemoni AS menurun, menurut Modelski pemimpin baru harus muncul setelah masa perang. Model Wallerstein menunjukkan bahwa skenario politik lain, tanpa satu keadaan dominan, dapat muncul (Flint 2006).

\subsection{Sistem Intrusif}

Dalam menganalisis topik penulisan ini, dapat terjawab dengan menggunakan kerangka pemikiran lanjutan, yakni teori "sistem intrusif" yang dicetuskan oleh Louis Cantori dan Steven Spiegel. Suatu permasalahan di kawasan tidak hanya dapat dilihat dari satu sisi pandangan. Secara jelas, topik ini telah menyebutkan adanya keterkaitan negara-negara di luar kawasan - Jepang maupun Tiongkok. 
Menurut Cantori dan Spiegel (1970), "An intrusive system consists of the politically significant participation of external powers in the international relations of the subordinate system. While the core and peripheral sectors both involve the states located within the region, an analysis of almost every region reveals that these states are not the only ones which play a role in the activities of the subordinate system."

Mereka memandang bahwa pembagian golongan di dunia ini, tidak hanya terbagi atas negara inti dan periferal, namun adapula keterlibatan negara-negara besar ekstra kawasan. Dampak yang ditimbulkan dari sistem intrusif dapat bersifat positif ataupun negatif. Dikatakan demikian, karena adanya negara besar di luar kawasan yang ikut mencampuri urusan di kawasan tertentu, hasilnya tergantung hubungan yang dilakukan antar negara, apakah menghasilkan harmonisasi atau terjadinya perang di kawasan.

Pada umumnya, sistem intrusif diperankan oleh beberapa negara besar ektra kawasan, yang memiliki tujuan-tujuan tertentu di dalam suatu kawasan. Cantori dan Spiegel menyebutkan, terdapat dua bentuk yang menjadi landasan negara-negara ekstra kawasan untuk berpartisipasi, yaitu "politically significant involvement and politically insignificant involvement. (Ibid.)" Keterlibatan politik signifikan diartikan dapat menghasilkan dampak hubungan yang mempengaruhi keseimbangan kekuatan dari sistem subordinat dan sistem dominan dalam suatu kawasan, sedangkan keterlibatan politik yang tidak signifikan biasanya tidak menghasilkan partisipasi politik yang berdampak pada keseimbangan kekuatan (Maya 2016). Untuk menjalakan keterlibatan tersebut, terdapat alat sebagai perantara, politik signifikan biasanya menggunakan kerjasama dalam bidang ekonomi dan militer, faktor kolonial, aliansi, komitmen pasukan militer dan beberapa perjanjian antar negara intrusif dan regional, sementara politik tidak signifikan menggunakan bantuan materi, perdagangan, investasi ekonomi, dan budaya hingga pendidikan (Ibid. 2016), yang mana dinilai tidak bersifat signifikan atau pasti secara berkala.

Cantori dan Spiegel juga mengklasifikasi beberapa indikator terkait dengan politik signifikan dan politik tidak signifikan, yang disebutkan dalam tulisannya yakni, "multilateral arrangement; bilateral arrangement; trade and economic investment; possession of a colony; military intervention; subversion; the United Nations; cultural and education activities; and propaganda." Ini, juga dapat disebut pula sebagai metode partisipasi bagi hubungan negara kawasan dengan negara ekstra kawasan. Untuk itu, berlandaskan teori sistem intrusif, penulis dapat mengkategorikan dua tujuan pembahasan, yaitu (1) menganalisa proses keterlibatan partisipasi politik sistem intrusif di kawasan Asia Tengah dan; (2) menemukan dampak dari sistem intrusif.

\section{Persebaran Sumber Daya Energi di Asia Tengah}

\subsection{Sumber Daya di Kazakshtan}

Sumber daya alam Kazakhstan yang paling penting adalah minyak dan gas. Cadangan minyak Kazakhstan diperkirakan menjadi yang terbesar ke-11 di dunia. Selama abad ke-21, industri minyak dan gas Kazakhstan telah tumbuh terutama karena investasi dari negara lain yang telah didorong oleh pemerintah. Kazakhstan memiliki berbagai sumber daya mineral seperti uranium dan garam yang merupakan beberapa sumber daya alam terpentingnya. Cadangan uranium Kazakhstan adalah yang terbesar kedua di dunia. Kazakhstan juga memiliki cadangan batu bara yang signifikan yang memiliki signifikansi ekonomi yang besar bagi negara tersebut. 
Gambar 2. Peta Kazakhstan

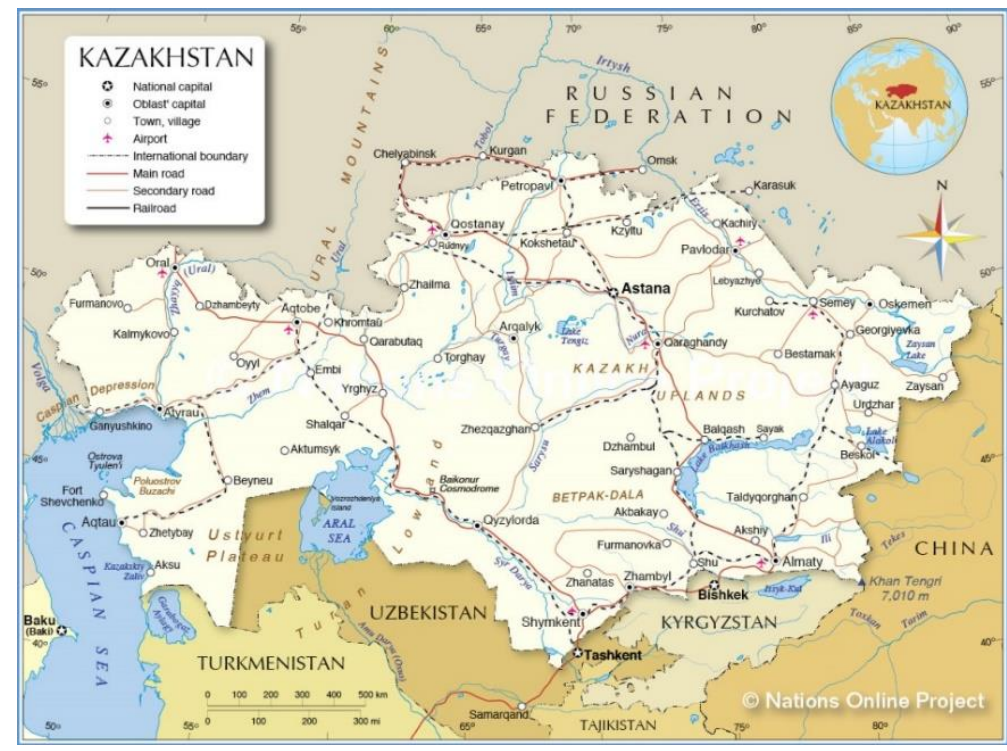

Sumber: nationsonline.org (Political Map of Kazakhstan 2019)

Kazakhstan memiliki sekitar 30 miliar barel cadangan minyak, bersama dengan 38,8 tcf (trillion cubic feet) gas alam. Ini adalah salah satu dari 15 negara teratas berdasarkan ukuran cadangan minyaknya. Mayoritas cadangan hidrokarbon Kazakhstan terletak di wilayah Kashagan, Tengiz dan Karachaganak. Ladang Kashagan, ditemukan pada tahun 2000 (The U.S. Energy Information Administration (EIA) 2017).

\subsection{Sumber Daya di Uzbekistan}

Penambangan, penggalian, dan minyak dan gas adalah industri utama ekonomi Uzbekistan. Negara ini adalah produsen gas alam terbesar ke-15 di dunia dan produsen emas terbesar ke-9. Sektor minyak dan gas menyumbang hampir 16 persen untuk Produk Domestik Bruto dan mempekerjakan lebih dari 120.000 orang. Cadangan hidrokarbon negara itu signifikan; menurut pejabat industri setempat, total cadangan energi primer (terbukti dan diproyeksikan) berjumlah 5,5 miliar ton minyak, termasuk 1,5-1,6 miliar ton gas alam, hingga 3,3 miliar ton batu bara. (The U.S. Energy Information Administration (EIA) 2016)

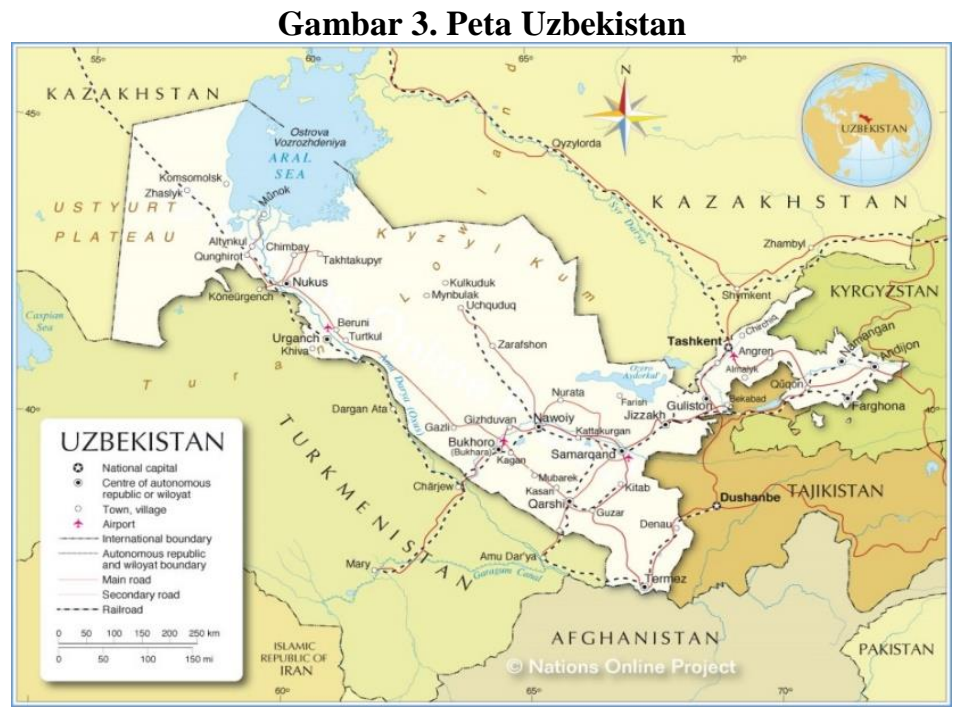

Sumber: nationsonline.org (Political Map of Uzbekistan 2019) 


\subsection{Sumber Daya di Turkmenistan}

Turkmenistan kaya akan sumber daya minyak dan terutama gas. Menurut angka resmi, basis sumber daya Turkmenistan adalah sekitar 71,64 miliar ton minyak, termasuk 53 miliar ton yang terletak di ladang darat dan 18,21 miliar ton di Laut Kaspia. Pemerintah Turkmenistan mengumumkan pada Konferensi Gas Turkmenistan Mei 2017 cadangannya adalah 50,4 triliun meter kubik (tcm). Namun, perkiraan internasional berbeda-beda. Tinjauan Statistik British Petroleum (BP) 2018 untuk Energi Dunia menunjukkan bahwa Turkmenistan, pada akhir 2017, memiliki 100 juta ton cadangan minyak yang terbukti dan 19,5tcm gas. Menurut laporan yang sama, Turkmenistan, dengan konsumsi tahunan lokal 28,4 bcm gas, menghasilkan $62 \mathrm{bcm}$ gas alam pada 2017 dan mengekspor 33,6 bcm pada 2017, 31,7 ke Cina (The U.S. Energy Information Administration (EIA) 2016).

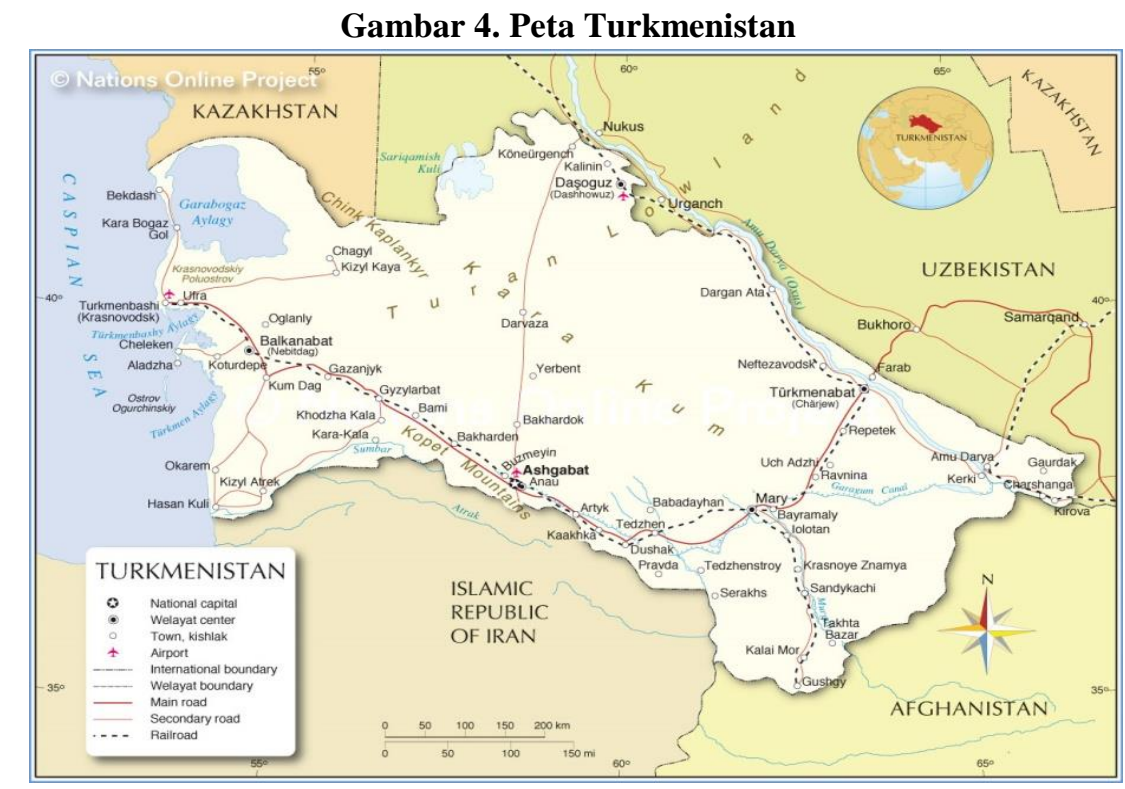

Sumber: nationsonline.org (Political Map of Turkmenistan 2019)

\section{Eksistensi Jepang dan Tiongkok di Asia Tengah}

Keberadaan Jepang di Asia Tengah telah berlangsung lama. Secara historis, keharmonisan hubungan keduanya dapat ditelusuri dengan tiga fase utama. Fase pertama, ditinjau setelah Perang Dunia Kedua, apalagi, sejumlah tawanan perang Jepang (prisoners of war) dibawa ke beberapa republik di wilayah tersebut seperti, Uzbekistan dan Kazakhstan, kemudian para tawanan ikut terlibat dalam proses rekontruksi. Kualitas pekerjaan tawanan perang di situs konstruksi meninggalkan kesan yang sangat baik. Ketika runtuhnya Uni Soviet setelah Perang Dingin tahun 1991, republik-republik Asia Tengah mencapai kemerdekaannya masing-masing, perkembangan hubungan keduanya terus berkembang dan menjadi kuat (Dadabaev 2011). Secara bersamaan, peran Silk Road atas hubungan ini juga dinilai penting sebagai ajang unjuk diri Jepang agar mendapat simpatisan dan kepercayaan di lingkungan Asia Tengah.

Fase kedua terjadi dimulai pada tahun 1997, seorang yang bernama Keizo Obuchi sebagai representative Jepang, yang ingin membangun hubungan diplomatik dengan negaranegara kawasan Asia Tengah. Pada saat itu, ia melakukan perjalanan mengelilingi Asia Tengah dan dikenal dengan "Misi Keizo Obuchi. (Mangi 2011)" Selanjutnya, di tahun yang sama Perdana Menteri Ryutaro Hashimoto memberikan deklarasi terkait hubungan antar 
negara yang akan terjalin di tahun-tahun berikutnya seperti, yang secara umum dikenal sebagai "Diplomasi Eurasia," "Misi Energi Jalur Sutra" tahun 2002, dan "Dialog Asia Tengah+Jepang" tahun 2004. Kebijakan-kebijakan Jepang terhadap Asia Tengah didukung dengan pemberian bantuan dana melalui sistem Official Development Assistance (ODA). Sumbangan ODA oleh Jepang untuk lima negara Asia Tengah pada tahun 1993 adalah \$2,57 juta AS. Ini mencapai 108,48 juta dolar AS pada 2008 (Ibid.).

Fase ketiga merupakan lanjutan dari deklarasi yang telah dinyatakan oleh Jepang yang dimulai di tahun 2004 untuk menunjukkan keseriusan langkah-langkah diplomatik untuk Asia Tengah. Dibuktikan dengan berkembangnya "Dialog Asia Tengah+Jepang" dan bersamaan dengan Divisi Asia Tengah dan Kaukus yang didirikan di Kementerian Luar Negeri Jepang. Selama fase ini Jepang berinteraksi dengan Republik Asia Tengah di tiga tingkat: hubungan diplomatik / politik; perdagangan, dan investasi; dan, bantuan dan bantuan (Ibid.). Periode ini menunjukkan proses keterlibatan Jepang untuk masuk ke dalam lingkaran kehidupan Asia Tengah. Demi mempertahankan eksistensinya semasa menjadi tahanan perang dan untuk memperluas hubungan kerjasama, Jepang dengan gigih dan menggunakan cara secara berhatihati, berhasil masuk dan diakui keberadaannya. Sehingga, perlahan kebijakan Jepang dapat mempengaruhi kebijakan di kawasan Asia Tengah.

Terjalinnya kerjasama Jepang dan Asia Tengah juga tersirat kepentingan utama yang menjadi urgensi hubungan keduanya. Telah diketahui bahwa kawasan Asia Tengah mengandung sejumlah sumber energi yang besar, hingga besarannya bisa menandingi kawasan Timur Tengah. Menurut suatu laporan, Kazakhstan memiliki 15 persen uranium dunia, dan masing-masing tiga dan empat persen dari minyak dan batubara dunia. Negara ini memiliki cadangan kromit, seng, dan timbal terbesar di dunia. Lima persen dari cadangan gas alam dunia terletak di Turkmenistan. Negara lain Uzbekistan memiliki 0,8 persen dari cadangan gas alam dunia. Menurut Buku Mineral Tahun 2010 negara itu, Uzbekistan memiliki 5300 metrik ton emas (Shaikh 2018). Sumber daya alam ini sebagian besar belum dimanfaatkan. Cadangan minyak negara-negara yang terletak di Teluk Persia adalah sumber utama pasokan minyak ke dunia. Dengan demikian, pentingnya sumber daya alam yang terletak di kawasan Asia Tengah tidak boleh diabaikan dalam Pertandingan Besar, urusan internasional global yang dapat memenuhi kebutuhan energi dunia saat ini dan masa depan. Pemilik dari sumber-sumber energi yang melimpah tersebut dijuluki sebagai The Big Three, negara-negara tersebut ialah Turkmenistan, Kazakhstan dan Uzbekistan (Olimat 2017). Oleh karena itu, Jepang memiliki minat besar di kawasan Asia Tengah, terutama dalam segi energi.

Tidak luput dari persaingan, kontestasi Jepang bukan tidak memiliki hambatan atau pesaing. Jepang memiliki tugas besar untuk dapat menandingi pesaing besar lain yang berada di geografis yang bertetangga dan kuat. Tiongkok merupakan negara besar lainnya yang turut mengambil andil di kawasan Asia Tengah. Dalam perbincangan dunia, keberadaan Tiongkok lebih besar dalam hal keamanan, walaupun tidak dipungkiri bahwa sumber energi juga menjadi tujuan utamanya. Persaingan keduanya hingga kini tidak sampai menimbulkan perang terbuka, tetapi mereka secara langsung bersaing melalui ide kerjasama, dan menunjukkan langkah kerjasama mana yang jauh lebih baik.

Tiongkok mengartikan keberadaan Jepang tidak lain adalah sebagai representatif Amerika Serikat. Mengingat kejadian setelah Perang Dunia Kedua, yang kemudian menjadikan Jepang sebagai sekutu Amerika Serikat. Selain itu, Tiongkok memiliki memori kelam dengan Jepang yang sempat menduduki Manchuria dan Taiwan (Ibid.). Pembalasan lainnya, yaitu sengketa pulau Senkaku/Diaoyu yang berada di Laut Cina Timur dan hak navigasi di Laut Cina Selatan dan Timur. Walaupun demikian, Jepang dan Tiongkok tetap menjalankan kerjasama mutualisme di berbagai bidang.

Persaingan tetap menjadi tolok ukur, untuk menunjukkan kekuatan masing-masing negara, jika dibandingkan Jepang belum dapat sejajar dengan negara-negara adidaya di dunia 
saat ini. Namun, hal itu tidak menghentikan langkah Jepang untuk turut serta dalam kontestasi fora internasional. Perang ide yang muncul sebagai tandingan kerjasama Tiongkok di Asia Selatan yang dicetuskan oleh Jepang, yakni Arc Central Freedom and Prosperity Initiative (AFPI). AFPI dipercaya dapat mendorong lebih kuat lagi dalam kerjasama Jepang dan Asia Tengah, dan dapat menandingi inisiatif One Belt One Road (OBOR) yang diusulkan oleh Xi Jinping selama kunjungannya ke Kazakhstan pada 2013. Niat AFPI adalah untuk membimbing asing Tokyo - kebijakan menuju Asia Tengah, Asia Tenggara, Timur Tengah, Eropa Tengah, ASEAN, dan kawasan Eurasia. Namun, OBOR Tiongkok lebih berhasil membangun kerangka kerja sama jangka panjang dengan mitra di Asia Tengah, Timur Tengah, Timur Jauh, Afrika, Eropa, dan Amerika Latin. OBOR, SCO, dan CICA paling menarik bagi mitra Tiongkok di Asia Tengah, jantung dari Jalur Sutra kuno dan saat ini. Tiongkok memenuhi wilayah ini dengan miliaran dolar dalam investasi langsung di sektorsektor seperti minyak, gas, konstruksi, industrialisasi, telekomunikasi dan konektivitas, transportasi, kereta api, perbankan, transfer teknologi, industri teknologi tinggi, serta barang dan jasa konsumen. Investasi besar-besaran Tiongkok dalam OBOR-nya tidak tertandingi. Tidak seperti OBOR atau Uni Bea Cukai Rusia, kesulitan yang dihadapi AFPI beragam. Hal itu disebabkan karena tidak memiliki kerangka kerja intelektual yang dibangun di atas kesamaan dan narasi bersama. Ini juga tidak memiliki kemampuan untuk menggunakan prinsip-prinsip dasar hubungan internasional seperti politik keterkaitan, saling ketergantungan, atau saling ketergantungan yang kompleks jika dibandingkan dengan kerangka kerja sama Tiongkok-Asia Tengah dan kemitraan strategis Tiongkok-Rusia (Ibid.).

\section{Kesimpulan}

Geopolitik energi sebagai perimbangan kekuasaan di antara negara dan perusahaanperusahaan dalam rangka mengakses sumber daya energi serta melakukan pengaturan terhadap sumber daya dan isu-isu terkait energi. Dalam konteks ini, arena geopolitik energi berada di kawasan Asia Tengah, yang merupakan negara-negara pecahan Uni Soviet. Secara geografis, kawasan ini dikelilingi oleh dua negara adidaya, yaitu Tiongkok dan Rusia. Namun, karena terdapat sumber energi yang melimpah di perut buminya, kawasan ini menjadi target bagi beberapa negara - termasuk Jepang. Saat ini, Jepang termasuk dalam jajaran negara kuat dan kaya, tetapi tingkat keberadaannya belum dapat menandingi negara adidaya, Tiongkok yang bertetangga dengan kawasan Asia Tengah. Jepang dan Tiongkok hingga kini masih tetap bersaing satu sama lain dengan tujuan utama yang berbeda. Kehadiran Jepang dikhawatirkan sebagai representatif Amerika Serikat, sehingga keberadaan Tiongkok sangat diperlukan untuk meminimalisir perluasan kekuasaan AS. Sementara itu, kepentingan utama Jepang diyakini untuk menguasai sumber energi yang berlimpah di kawasan Asia Tengah. Keduanya saling bertarung ide kerjasama untuk mengambil simpati dan kepercayaan di Asia Tengah. AFPI merupakan alat yang diluncurkan Jepang untuk menandingi OBOR Tiongkok, sayangnya, banyak hambatan dan kekurangan yang dihadapi AFPI. Sejauh ini, persaingan keduanya terbilang kondusif, bila ditinjau menggunakan pandangan sistem intrusif, dampak yang dihasilkan tergolong dalam dampak yang positif (keharmonisasian) bukan dampak negatif (perang terbuka). 


\section{DAFTAR PUSTAKA}

\section{Buku}

Chevalier, Jean-Marie. 2009. "The New Energy Crisis"dalam The New Energy Crisis: Climate, Economics and Geopolitics. New York: Palgrave Macmillan.

Flint, Colin. Introduction to Geopolitics. New York: Routledge, 2006.

\section{Jurnal}

Dadabaev, Timur. 2011. "The Evolution of Japanese Diplomacy towards Central Asia since the Collapse of the Soviet Union: Yearbook on the Organization for Security and Cooperation in Europe (OSCE) ." OSCE yearbook.

Olimat, Muhamad S. 2017. "The Geopolitics of Energy in Central Asia Rivalry And Accomodation." Energy Studies Unit.

\section{Website}

Nations Online. Political Map of Kazakhstan (also spelled Kazakstan, Kazakiya,Qazakiya). 2019. https://www.nationsonline.org/oneworld/map/kazakhstan-political-map.htm (accessed Mei 19, 2019).

Nunlist, Christian, and Matthias Bieri. "Putin's Next Steppe : Central Asia and Geopolitics." CSS Analyses, 2016: 2.

Shaikh, Khalil-ur-Rahman. 2018. Japan's relations with Central Asia. April 26. Accessed Mei 25, 2019. https://dailytimes.com.pk/232415/japans-relations-with-central-asia/.

The U.S. Energy Information Administration (EIA). Kazakhstan Energy Profile: SecondLargest Oil Reserves Among Former Soviet Republics - Analysis. Mei 6, 2017. https://www.eurasiareview.com/06052017-kazakhstan-energy-profile-second-largestoil-reserves-among-former-soviet-republics-analysis-2/ (accessed Mei 19, 2019).

—. Turkmenistan. Juli 2016. https://www.eia.gov/beta/international/analysis.php?iso=TKM (accessed Mei 19, 2019).

-. Uzbekistan. Juli 2016. https://www.eia.gov/beta/international/analysis.php?iso=UZB (accessed Mei 19, 2019). 